\title{
Intraductal Carcinoma of Prostate (IDC-P), Grade Group, and Molecular Pathology: Recent Advances and Practical Implication
}

\author{
Ashwyna Sunassee ${ }^{1 *}$, Ghadah Al Sannaa ${ }^{1 *}$, Jae Y. Ro
}

Cite this article: Sunassee A, Al Sannaa G, Ro JY: Intraductal carcinoma of prostate (IDC-P), grade group, and molecular pathology: recent advances and practical implication. Ann Urol Oncol 2019; 2(1): 9-18. https://doi.org/10.32948/ auo.2019.03.11

\begin{abstract}
The Gleason grading system for prostatic carcinoma is widely used internationally and is based on microscopic architectural patterns of tumors. Over the years, there have been modifications to the original grading system established by Donald F Gleason in 1966 and refined in 1974 which have subsequently been established by the World Health Organization in its WHO Classification of Tumors of the Urinary System and Male Genital Organs book, published in 2016. There have been certain practical issues associated with the changes, of note, the addition of intraductal carcinoma of prostate (IDC-P), which unlike its breast counterpart rarely occurs in isolation without association with invasive carcinoma and tends to be associated with high-grade invasive carcinoma. In addition, the Grade group system has been introduced which categorizes tumors into prognostically relevant groups based on the histological grade scores. The grade group system brings to light the importance of making accurate scoring and subsequent grouping of the tumors as it affects the clinical treatment, prognostic implication and stage assignment. Molecular pathology of the prostate is not widely utilized in clinical practice, but is emerging. The most common genomic aberration in prostate cancer includes gene fusion, amplification, deletion, and mutation. In addition, up and down regulation of gene expression in critical cellular pathways is also at play. A series of long noncoding RNA expression changes have been also unveiled from transcriptome sequencing data. They play a regulatory role in prostate cancer and are promising diagnostic and potentially prognostic markers as well as molecular treatment strategy. In this review, we summarize recent advances in molecular pathology of prostate cancer and their emerging clinical utility with currently available molecular tests. In this review article, we discuss the followings: 1) Gleason grading system with its modification, 2) Grade group, 3) Intraductal carcinoma, and 4) molecular pathology. Additionally, we present that molecular studies continue to emerge, and there is significant opportunity for targeted therapeutic options that remains to be explored in depth.
\end{abstract}

Key words prostatic carcinoma, gleason scoring system, grade group system, Intraductal carcinoma of prostate (IDC-P), molecular testing

\footnotetext{
1. Department of Pathology and Genomic Medicine, Houston Methodist Hospital, Weill Medical College of Cornell University, Houston, TX, USA.

*: A. Sunassee and G. Al Sannaa contributed equally to this work.

Correspondence: Jae Y. Ro (Department of Pathology and Genomic Medicine, Houston Methodist Hospital, Weill Medical College of Cornell University, 6565 Fannin Street, Houston, TX, USA; Email: jaero@houstonmethodist.org).
} 


\section{Introduction}

The current grading system for prostatic carcinoma that is used worldwide has evolved from the Gleason scoring system developed by Donald F Gleason in 1966 and refined in 1974 [1, 2]. Dr. Gleason developed a unique method to grade prostatic carcinoma based solely on microscopic architectural patterns of tumors (Figure 1). Based on the presence of nodular versus infiltrative patterns, the tumors are divided into patterns 1 and 2 versus 3-5. Patterns 1 and 2 tumors are nodular tumors with relatively well demarcated from the surrounding benign prostate glands without any infiltrating glands into the adjacent prostate tissue. Pattern 3 tumors are composed of single well-formed isolated glands. Pattern 4 tumors are characterized by: 1) ill- defined glands, 2) more than 3 glands fusion, and 3) glands with cribriform formation or glomerulation. Pattern 5 tumors are solid tumors, with isolated tumor cells or signet ring cells, or necrosis.

Subsequent clinicopathological studies led to significant modifications of the original system. In 2014, the International Society of Urological Pathology (ISUP) held a consensus conference to update the preceding 2005 grading system of prostate cancer (Figure 2) [3]. The updated grading system was adopted by the World Health Organization (WHO) in its WHO Classification of Tumors of the Urinary System and Male Genital Organs book, published in 2016 (Table 1) [4]. Subsequently, numerous studies highlighting practical issues on implementation of the new system, especially regarding the presence of intraductal carcinoma without invasive carcinoma, were published. Grade grouping is a stratification of histologic grade scores into prognostically relevant groups. The grade group system has been integrated into the American Joint Committee on Cancer (AJCC) staging system. The grade group is predictive for PSA recurrence and prostate cancer mortality (AJCC level of evidence I category prognostic factor) [5]. In contrast to intraductal carcinoma of the breast, intraductal carcinoma of the prostate (IDC-P) is nearly always associated with high volume, high grade, and advanced stage of invasive prostate carcinoma. The IDC-P likely represents an intraductal spread of the prostate carcinoma from adjacent high-grade invasive carcinoma. However, isolated IDC-P without concomitant prostate carcinoma has rarely been reported in $0.006-$ $0.26 \%$ of prostate biopsies, raising the possibility that it may represent a precursor lesion [6].

\section{Gleason grading system}

\section{Gleason scoring system}

The prostate cancer grading system currently used was developed by Donald F Gleason in 1966. It is a very unique system as compared to the standard method of grading used for other cancers in the sense that it is based solely on the architectural pattern of the tumor, and the total score is based on the sum of the most common grade patterns. This is in contrast to most other cancers in which the grading also takes into account the nuclear grade, and the highest grade is usually the one reported. The sum of the primary/ predominant pattern and the secondary/ second most prevalent architectural pattern originally gave the Gleason score, but now the Gleason score changed to be assigned as the sum of the primary/ predominant pattern and the worst architectural pattern. Gleason scores 2-5 should not be assigned on needle biopsies due to the poor reproducibility and poor correlation with the grade on radical prostatectomy [7]. Most cases tend to show a higher

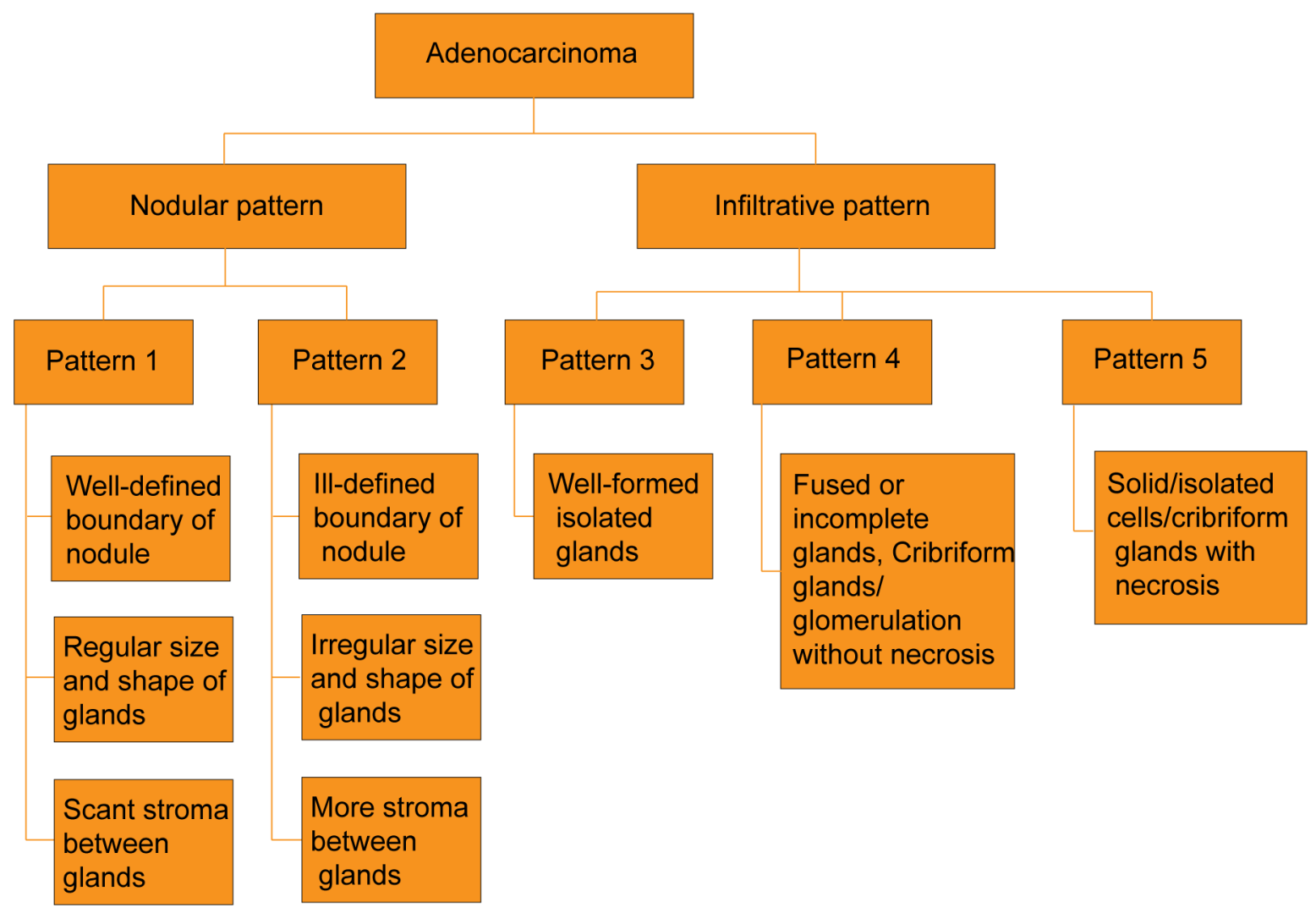

Figure 1. Algorithmic approach of Gleason grading system. 
grade on resections and clinicians and patients may have a false impression of an indolent diagnosis. Gleason pattern 3 consists of well-formed, discrete individual glands. It should be noted that a few poorly formed glands may represent tangentially sectioned glands which are acceptable within the spectrum of pattern 3 . Pattern 4 includes cribriform glands, some of which in the past have been called pattern 3 . However, studies have demonstrated the adverse prognosis, thus they are better categorized as pattern 4 regardless of size or marginal irregularity [8]. Small and large cribriform glands are equally linked to progression after radical prostatectomy (redefined at the $2014 \mathrm{WHO} / \mathrm{ISUP}$ conference) [9]. In addition, there was poor reproducibility in the past of what was considered as cribriform pattern grade 3 [10]. Glands with glomerulation are also considered a variant of cribriform glands and should be included under pattern 4 , and glomerulation pattern 4 is more reproducible. Unequivocal presence of incomplete glands (not tangential sectioning) and glandular fusion are also classified as Gleason pattern 4. Gleason pattern 5 is comprised of sheets of tumor cells, solid growth pattern, individual cells and individual array. Unequivocal comedo necrosis, which is different from intraluminal secretion, is considered pattern 5 , and is frequently associated with cribriform glands.

As a result of these changes, a number of tumors that were previously classified as pattern 3 are now considered pattern 4 . Consequently, a number of tumors have been reclassified from Gleason score 6 to Gleason score 7. Pure Gleason score 6 tumors essentially lack progression after radical prostatectomy with the risk for progression being almost zero $(0.4 \%)$ [11].

The other tumor group of interest is Gleason score 7. Numerous studies have been done, the majority of which show that the outcome for Gleason score $4+3$ has worse pathological stage and recurrence, as compared with Gleason score $3+4$ (these are all studies prior to the classification). Previously, any tumor with a pattern 4 component was considered to be high-grade. However studies show that Gleason score $3+4=7$ has a favorable prognosis when compared to Gleason score $4+3=7$. The latter has a behavior more similar to Gleason score 8 .

Gleason scores 8-10 used to be lumped together into one grade category. However, Gleason score 8 tumors have considerably worse prognosis than 6-7, although still better than Gleason score 9-10. Gleason score 9-10 tumors have almost twice the risk of progression compared to Gleason score 8. Gleason pattern 5 is the greatest risk factor for clinical failure and death from prostate cancer after dose-escalated radiation therapy and hormonal ablation [12].

The new consensus guidelines indicate that the term minor highgrade component should be used to replace a tertiary grade. Minor high-grade component indicates that the high grade component should not only be the third most prevalent pattern, but that it is also limited or minor in extent. No set percentage was agreed upon, however, the $5 \%$ cut-off is being used due to evidence based data correlating the outcome. This term should only be used on radical prostatectomy specimens when there are three grade patterns and less than $5 \%$ of pattern 5 . On needle biopsies, the higher grade is included in the Gleason score in any amount even less than 5\% of high-grade tumor. It was discussed at the 2014 Consensus Conference how minor high-grade patterns would be handled if Grade Groups 1 to 5 eventually were to replace Gleason scores 2 to 10 .

Certain considerations need to be taken into account if there is a small amount of cancer of a lower or higher grade. If there is a high-grade cancer present on needle biopsy or prostatectomy specimen, and the lower grade cancer comprises less than 5\%, then the lower grade should be ignored. An example is in the setting of Gleason pattern 4 and less than 5\% pattern 3, the score should be Gleason score of $8(4+4)$ ignoring pattern 3 component. However,

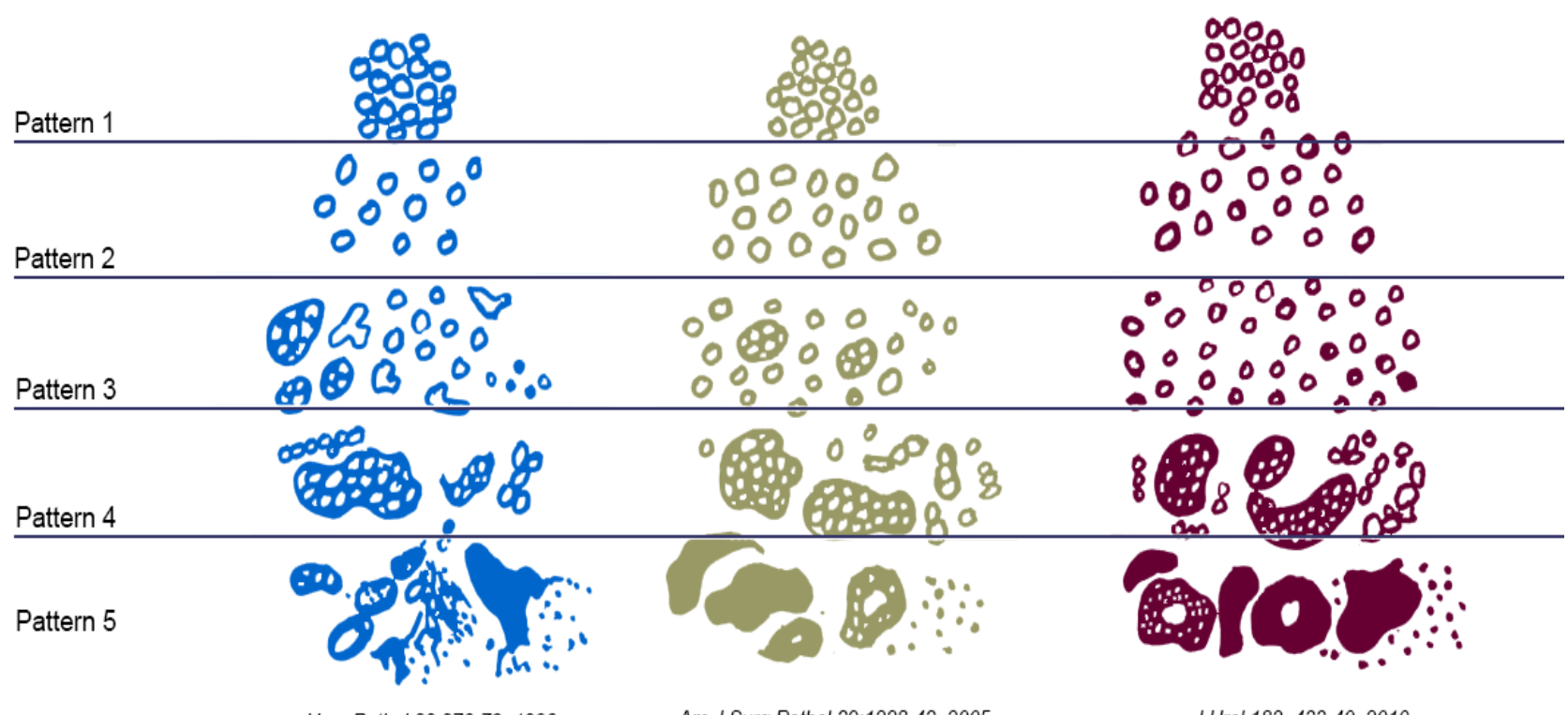

Figure 2. Gleason grading system evolution. Scores 2-5 are no longer assigned on biopsies (no pattern 1 or 2 on biopsies). The major change from the original Gleason scoring to the ISUP 2005 Gleason score suggested that cribriform glands should be small and well circumscribed to be classified as pattern 3. The WHO/ISUP 2014 scoring eliminated cribriform glands from pattern 3, and recommended that they should be classified as pattern 4. Presence of necrosis with cribriform glands is classified as pattern 5. 


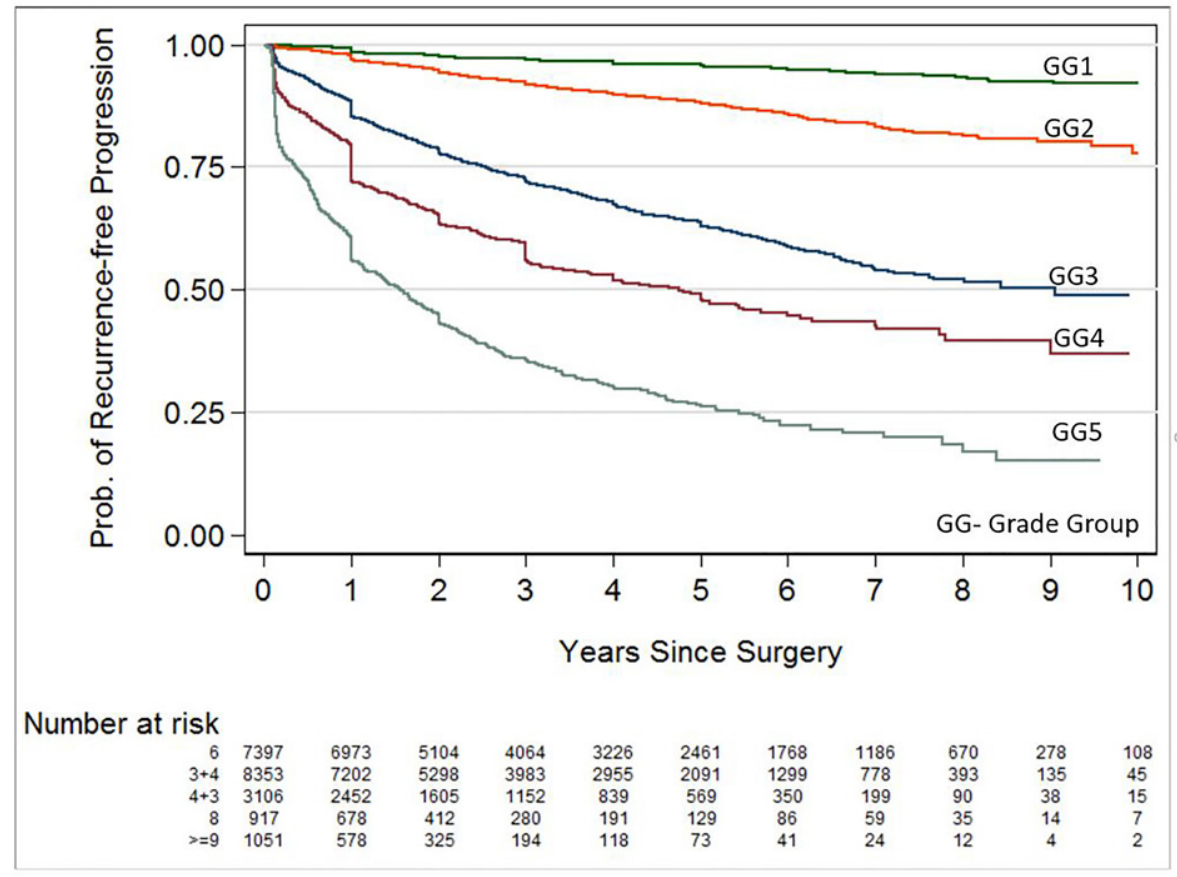

Figure 3. The five-year biochemical recurrence-free progression probabilities for radical prostatectomy Grade Groups $1-5$ were $96 \%, 88 \%$, $63 \%, 48 \%$, and $26 \%$, respectively. Figure adapted from Johns Hopkins Hospital, Department of Pathology.

on needle biopsy, when two grade patterns are present, the higher grade pattern should always be included in the Gleason score. In a radical prostatectomy specimen, if a tumor with Gleason score 7 $(4+3)$ but has more than $5 \%$ or $5 \%$ of pattern $5(>5 \%)$ in a nodule, pattern 5 is assigned as the secondary pattern for a Gleason score of $9(4+5)$. For radical prostatectomy specimens in which the highest grade is a Gleason score of 7, it is recommended that the percentage of pattern 4 be reported due to prognostic implications, which will be discussed later.

In radical prostatectomy specimens, individual tumor nodules are assigned a separate Gleason score.

Grade Groups

Table 1. Prostatic adenocarcinoma grade groups.
The new Grade group system (Table 1) is based on several studies that addressed the clinicopathological outcome in patients with prostate carcinoma. Despite being based on architectural patterns that were modified from those originally described by Gleason, the new system shows the natural history of prostate carcinoma (Figure 3) and defines Gleason pattern 4 better. All cribriform glands and glands with glomerulation, regardless of size or circumscription, are assigned as pattern 4. Unequivocal presence of incomplete glands (not tangential section of glands) and glandular fusion are also classified as Gleason pattern 4 (Figure 4). The distinction between patterns 4 and 3 is very important, especially for active surveillance protocol [13], because the presence of a component with pattern 4 automatically eliminates consideration for active surveillance in certain protocols (Table 2

\begin{tabular}{|c|c|}
\hline Grade & Standards \\
\hline Grade group 1 & $\begin{array}{l}\text { Gleason score } \leq 6 \\
\text { Only individual discrete well-formed glands }\end{array}$ \\
\hline Grade group 2 & $\begin{array}{l}\text { Gleason score } 3+4=7 \\
\text { Predominantly well-formed glands with lesser component of poorly formed/fused/cribriform glands }\end{array}$ \\
\hline Grade group 3 & $\begin{array}{l}\text { Gleason score } 4+3=7 \\
\text { Predominantly poorly formed/fused/cribriform glands with lesser component of well-formed glands }\end{array}$ \\
\hline Grade group 4 & $\begin{array}{l}\text { Gleason score } 4+4=8 ; 3+5=8 ; 5+3=8 \\
\text { - Only poorly formed / fused / cribriform glands or } \\
\text { - Predominantly well-formed glands and lesser component lacking glands or } \\
\text { - Predominantly lacking glands and lesser component of well-formed glands }\end{array}$ \\
\hline Grade group 5 & $\begin{array}{l}\text { Gleason score } 9-10 \\
\text { Lack gland formation (or with necrosis) with or without poorly formed/fused/cribriform glands }\end{array}$ \\
\hline
\end{tabular}



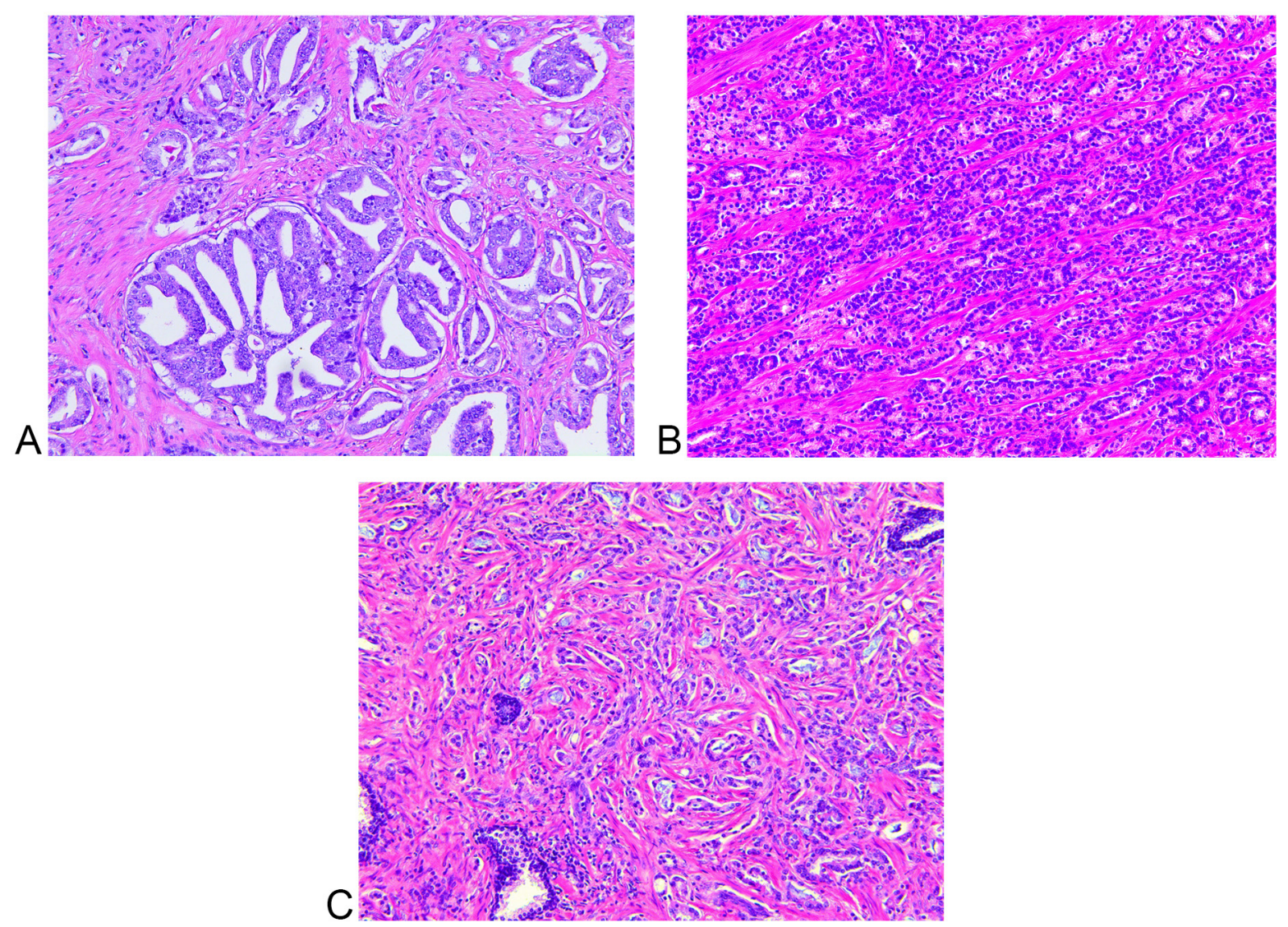

Figure 4. Representative images of Gleason pattern 4. (A) Cribriform glands, (B) Fused glands, and (C) Incomplete glands. Distinction from pattern 3 (distinct well-formed glands) is very important in terms of prognosis and treatment selection. All H\&E, X100.

) $[13,14]$. Therefore, we recommend conservative assignment of pattern 3 in cases of tumor glands that are not definite for either pattern 3 or 4 .

Despite the Gleason scoring system's benefits, it has not been infallible. One of the instances of such is that the Gleason score of 7 can be achieved by both $3+4$ and $4+3$ patterns which have been found to have very different prognostic impacts. A study done by Pierorazio et al [15] demonstrated that the Gleason grade groups are among the strongest predictors of biochemical recurrence-free survival (BFS).

The ISUP 2014 consensus conference decided that the Gleason scores would be grouped into five prognostically distinct categories, 1 to 5. Grade group 1 constitutes a Gleason score of less or equal to 6 , essentially a pattern of $3+3$. Such tumors have only individual discrete well-formed glands. Due to the new recommendations of including any high grade component on biopsies in the Gleason scoring system, Grade group 1 tumors are not expected to include any higher grade than pattern 3 component on the biopsies. Grade group 2 includes tumors with a Gleason score of $3+4=7$, such that the majority of the tumor is composed of well-formed glands with a lesser component of poorly formed/ fused/cribriform glands. Grade group 3 includes tumors with a Gleason score of $4+3=7$, in which the majority of the tumor is poorly formed/fused/cribriform glands with a lesser component of well-formed glands. The caveat of this grade group with the new guidelines is that if there is less than $5 \%$ of pattern $3 /$ wellformed glands, this would not be accounted into the grade groups and the tumor will rather be graded as $4+4=8$, grade group 4 . Grade group 4 includes Gleason score of $4+4=8,3+5=8$ and $5+3=8$. Grade group 5 includes Gleason scores of 9 and 10 These tumors lack gland formation, may have necrosis, with or without poorly formed/fused/cribriform glands. There is a debate about the behavior of $5+3=8$, in which it is thought to behave more similarly to Gleason score 9 tumors. The practice grading mentioning both the Gleason score and Gleason grade group thus should be practiced to ensure that the clinicians get all the information they may need and thus treat accordingly. One of the most impactful changes of the Gleason groups is the necessity to stratify Gleason group 7, which can now be Gleason group 2 or 3 depending on the amount of pattern 4 component. Grade group 2 or 3 is important to determine the final AJCC prognostic stage group because grade group 2 is Stage IIB, but grade group 3 is Stage IIC (Grade group 5 in any $\mathrm{T}$ or $\mathrm{N}$ stage belongs to Stage IIIC). It is especially important to identify the patients with a small component of pattern 4 , usually less than $10 \%$, as these patients may be candidates for active surveillance. Grading of intraductal carcinoma of the prostate, discussed further below, is not recommended.

The new Grade group system was implemented in an attempt to address the previously encountered deficiencies associated with the original Gleason score system. Despite the improved correlation with the clinical outcome of the patients, the newly developed grading system still elicits potential practical issues. One concern involves Grade group 4 (score 8), which includes: 1) exclusively pattern $4(4+4)$ tumor, 2$)$ predominantly pattern 3 $(3+5)$ tumor, or 3 ) predominantly pattern $5(5+3)$ tumor. A recent study demonstrated that the prognosis is not different in cancers with Gleason score $3+5=8$ and $4+4=8$ [16]. However, there are limited data on tumors with a score $5+3$ to conclude if these tumors are similar to Grade group 4 or group 5. Additional studies are needed to further sub-stratify cases with predominantly pattern 5 versus 3. Moreover, cases exhibiting equal amounts of patterns 
Table 2. Participant Characteristic and Inclusion Criteria for Several Large Active Surveillance Cohorts (Adapted from Active Surveillance in Prostate Cancer Patients - Amin et al.).

\begin{tabular}{|c|c|c|c|c|c|c|c|c|}
\hline \multirow[b]{2}{*}{ Source, year } & \multirow[b]{2}{*}{$\begin{array}{l}\text { Patients, } \\
\text { No. }\end{array}$} & \multirow[b]{2}{*}{ Age, year } & \multirow[b]{2}{*}{$\begin{array}{l}\text { Nonwhite, } \\
\%\end{array}$} & \multicolumn{5}{|c|}{ Inclusion Criteria } \\
\hline & & & & $\begin{array}{l}\text { C l i n i c a l } \\
\text { Stage }\end{array}$ & $\begin{array}{l}\text { PSA, ng/ } \\
\text { mL }\end{array}$ & $\begin{array}{l}\text { Gleason } \\
\text { Score }\end{array}$ & $\begin{array}{l}\text { Prost a te } \\
\text { Biopsy, }{ }^{a}\end{array}$ & $\begin{array}{l}\text { O t h e r } \\
\text { Criteria }\end{array}$ \\
\hline Lin et al, 2013 & 351 & $63.8^{\mathrm{b}}$ & 9 & $\leq \mathrm{T} 2$ & $\leq 10$ & $\leq 7(3+4)$ & $\leq 33 \mathrm{~A}$ & \\
\hline $\begin{array}{l}\text { Cooperberg et al, } \\
\text { 2011; and Glass } \\
\text { et al, } 2012\end{array}$ & 640 & $62^{\mathrm{c}}$ & 18 & $\leq \mathrm{T} 2$ & $\leq 10$ & $\leq 6$ & $\leq 33 \mathrm{~B}$ & \\
\hline Klotz et al, 2010 & 453 & $70^{\mathrm{c}}$ & NR & NA & $\leq 15$ & $\leq 7(3+4)$ & $\leq 50 \mathrm{C}$ & \\
\hline $\begin{array}{l}\text { Selvadurai et al, } \\
2013\end{array}$ & 471 & $66^{\mathrm{c}}$ & NR & $\leq \mathrm{T} 2 \mathrm{a}$ & $\leq 15$ & $\leq 7(3+4)$ & $\leq 50 \mathrm{~B}$ & \\
\hline $\begin{array}{l}\text { Adamy et al, } \\
2011\end{array}$ & 238 & $64^{c}$ & NR & $\leq \mathrm{T} 2$ & $\leq 10$ & $\leq 6$ & $\leq 3 \mathrm{D}, \leq 50 \mathrm{C}$ & \\
\hline Bul et al, 2013 & 2494 & $65.8^{\mathrm{c}}$ & NR & $\leq \mathrm{T} 2$ & 10 & $\leq 6$ & $\leq 2 \mathrm{D}$ & $\begin{array}{l}\text { PSAD } \leq \\
0.20\end{array}$ \\
\hline Patel et al, 2014 & 870 & $66^{\mathrm{c}}$ & 10 & Tlc & NA & $\leq 6$ & $\leq 2 \mathrm{D}$ & $\begin{array}{l}\text { PSAD } \leq \\
0.15\end{array}$ \\
\hline
\end{tabular}

Abbreviations: NR, not reported; PSA, prostate-specific antigen; PSAD, prostate-specific antigen density;

${ }^{a}$ Biopsy code: A, percentage of positive cores; B, percentage of cores; C, percentage of any core; D, No. of cores, ${ }^{b}$ Mean, ${ }^{c}$ Median; NA, not available.

3 and 5 need to be further explored. One can argue that it is better to re-classify tumors with predominant pattern 5 as Grade group 5. Further survival outcome studies are crucial in order to develop a more evidence-based grading group system. Another important advancement involves use of the term Grade group 1 instead of Gleason score 6 to indicate that this represents an indolent tumor with good prognosis (Grade group 1 of 5). This also serves to relieve the mental anguish of clinicians and patients associated with a diagnosis of Gleason score 6 of 10 as opposed to Grade group 1 of 5 .

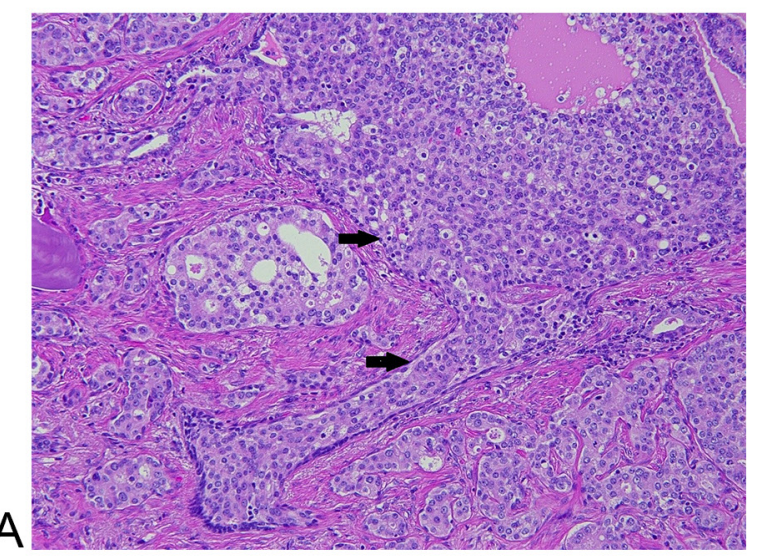

\section{Intraductal carcinoma of Prostate (IDC-P)}

\section{Background}

The history of IDC-P has been quite confusing over the years. The term has been used to describe prostatic ductal adenocarcinoma, prostatic acinar adenocarcinoma, and even extension of urothelial carcinoma into prostatic ducts and acini. It basically refers to prostatic carcinoma cells as well as squamous and urothelial carcinoma cells extending into prostatic ducts and acini including neoplastic prostate $[17,18]$. Kovi et al. had a different description

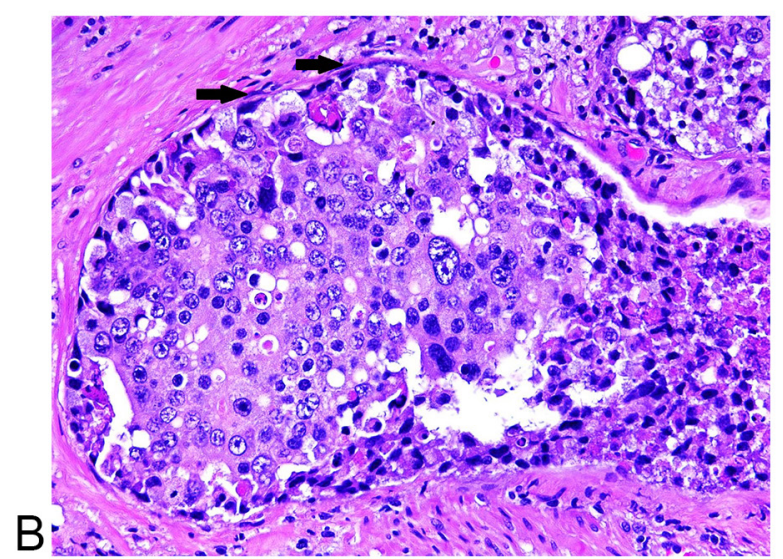

Figure 5. (A) Intraductal carcinoma with dense cribriform formation, central necrosis, and ill-defined boundary. Note the presence of basal cells (arrows) in intraductal carcinoma component, and an adjacent high grade invasive carcinoma. (B) Intraductal carcinoma with significant pleomorphism. Note the presence of basal cells (arrows) in intraductal carcinoma component. A. H\&E, X100 and B, H\&E, X400. 
Table 3. Commercially available Genetic Assays based on somatic mutations within prostate cancer tumors (Adapted from European Urology Supplements, Volume 16, Issue 12, December 2017, Pages 253-271) .

\begin{tabular}{|c|c|c|c|c|c|}
\hline $\begin{array}{l}\text { Propos e d } \\
\text { Utility }\end{array}$ & \multicolumn{2}{|c|}{$\begin{array}{l}\text { Distinguish between aggressive and } \\
\text { non-aggressive prostate tumors }\end{array}$} & \multicolumn{2}{|c|}{$\begin{array}{l}\text { Determine need for repeat biopsy after } \\
\text { a negative prostate biopsy }\end{array}$} & $\begin{array}{l}\text { D e t e r m i n i } \mathrm{n} \mathrm{g} \\
\text { metastasis after radical } \\
\text { prostatectomy }\end{array}$ \\
\hline Test Name & Prolaris & $\begin{array}{l}\text { Oncotype DX, } \\
\text { Prostate }\end{array}$ & Progensa PCA3 & $\begin{array}{l}\text { Mi-Prostate } \\
\text { Score }\end{array}$ & Decipher \\
\hline $\begin{array}{l}\text { Commercial } \\
\text { Company }\end{array}$ & Myriad Genetics & $\begin{array}{l}\text { G e n o m i c } \\
\text { Health, Inc }\end{array}$ & Gen-Probe (Hologic) & $\begin{array}{l}\text { University of } \\
\text { Michigan Labs }\end{array}$ & GenomeDX Biosciences \\
\hline Sample & $\begin{array}{l}\text { Prostate biopsy } \\
\text { tissue }\end{array}$ & $\begin{array}{l}\text { Prostate biopsy } \\
\text { tissue }\end{array}$ & Urine & Urine, Serum & Prostate tissue \\
\hline Measures & $\begin{array}{l}\text { 48-gene expression } \\
\text { panel involved in cell } \\
\text { cycle progression }\end{array}$ & $\begin{array}{l}17-\mathrm{g} \text { e } \mathrm{n} \text { e } \\
\text { expression } \\
\text { panel involved } \\
\text { in multiple } \\
\text { pathways }\end{array}$ & $\begin{array}{l}\text { P C A } 3 \text { g e n e } \\
\text { expression }\end{array}$ & $\begin{array}{l}\text { TMPRSS2-ERG, } \\
\text { PCA3, PSA }\end{array}$ & $\begin{array}{l}22 \text {-gene multi-pathway } \\
\text { expression panel }\end{array}$ \\
\hline
\end{tabular}

which was first described in 1985 , in which it was postulated that prostatic carcinoma involved pre-existing prostate ducts and acini. Intraductal spread was found in nearly half of the 139 cases of prostatic adenocarcinoma that the authors studied; they speculated that the carcinoma cells penetrate the wall of benign ducts, and progressively replace the normal epithelial cells [19]. IDC-P is prostatic adenocarcinoma that extends into and proliferates within preexisting prostatic ducts. It can exhibit a variety of growth patterns including cribriform, solid, micropapillary and flat architecture.

IDC-P is defined as an intraductal and/or intra-acinar neoplastic epithelial proliferation that has features of high-grade prostatic intraepithelial neoplasia (HGPIN) but exhibits greater architectural complexity and/or cytological atypia. There are three important features to distinguish IDC-P from HGPIN in biopsies: 1) size $>1$ $\mathrm{mm}$ and number of cribriform glands $>6$ in IDC-P; 2) ill-defined boundary or branching contour, and dense or solid cribriform in IDC-P vs. well-defined boundary, and loose cribriform in HGPIN; 3) pleomorphism, defined as $>6$ times nuclear size difference compared to adjacent benign cells, and non-focal central comedo necrosis in IDC-P vs. less pleomorphism and absent/focal necrosis in HGPIN (Figure 5). In cases where the features are not distinct for either category, the term atypical cribriform lesion (ACL) is used and repeat biopsy is recommended [20]. Minor criteria for IDC-P that may be helpful, but are not diagnostic on their own include: 1) atypical glands that are irregular or branching at right angles, 2) increased mitotic activity with frequently identified mitotic figures and 3) two distinct cell populations comprising of an outer layer of pleomorphic, mitotically active cells and a central component of cuboidal, monomorphic cells without mitotic activity.

Immunohistochemistry may be helpful in the diagnosis of IDC-P by confirming the presence of basal cell layer around atypical glands. IDC-P is associated with aggressive prostatic adenocarcinoma and its presence in either core needle biopsy or radical prostatectomy specimens is associated with adverse prognosis.

Several published studies show that the presence of IDC-P correlates with higher Gleason scores, larger tumor volumes, and increased risk of extra prostatic extension, seminal vesicle invasion, and pelvic lymph node metastases.
Subsequent studies continue to suggest that IDC-P indicates ductal spread of malignant cells rather than a precursor lesion to invasive carcinoma, and are typically associated with higher grade tumors. Additionally, many studies demonstrated that IDC-P on a biopsy or prostate resection is an independent adverse prognostic factor even in the presence of metastatic disease [21]. Subsequently, some authors recommended definitive treatment in men with IDC-P in the absence of identifiable invasive carcinoma on needle biopsies. On rare occasion, an invasive carcinoma is not evident on radical prostatectomy performed due to IDC-P (identified on biopsy). These cases, without an identifiable invasive component likely suggest that a subset represents a precursor lesion in addition to IDC-P being a manifestation of ductal spread of invasive carcinoma (Figure 6). On biopsy, the incidence of isolated IDC-P is $0.1-0.3 \%$, and IDC-P associated with invasive carcinoma is $2.8 \%$. In radical prostatectomies, the incidence of IDC-P without invasive carcinoma is rare and is less than $0.1 \%$, whereas IDC-P associated with invasive carcinoma approaches 20 $40 \%$. In breast and endometrium, the in situ tumor components may be high- and low-grade. In the prostate, although rare, there may be dual carcinoma progression, one from high-grade PIN and the other from IDC-P. More studies are required to better define the precursor type of IDC-P.

A study by Van der Kwast et al, reported that the presence of IDC-P in prostate biopsies correlated with early biochemical failure and metastatic disease following radiation treatment in patients with intermediate or high-risk prostate cancer [22].

IDC-P represents late-stage progression of prostatic adenocarcinoma in the majority of cases with intraductal extension of high-stage, advanced cancer. This theory has been supported by molecular studies [23]. The majority of IDC-P cases show cytoplasmic loss of phosphatase and tensin homolog gene (PTEN) as opposed to the retained PTEN staining, seen in HGPIN. A greater frequency of loss of heterozygosity $(\mathrm{LOH})$ has been reported in up to $60 \%$ of IDC-P cases as compared to no loss on Gleason pattern 3 prostatic adenocarcinoma and rare loss in HGPIN cases.

\section{Intraductal Carcinoma and Gleason Grading}

ISUP recommends that IDC-P should not be graded regardless 


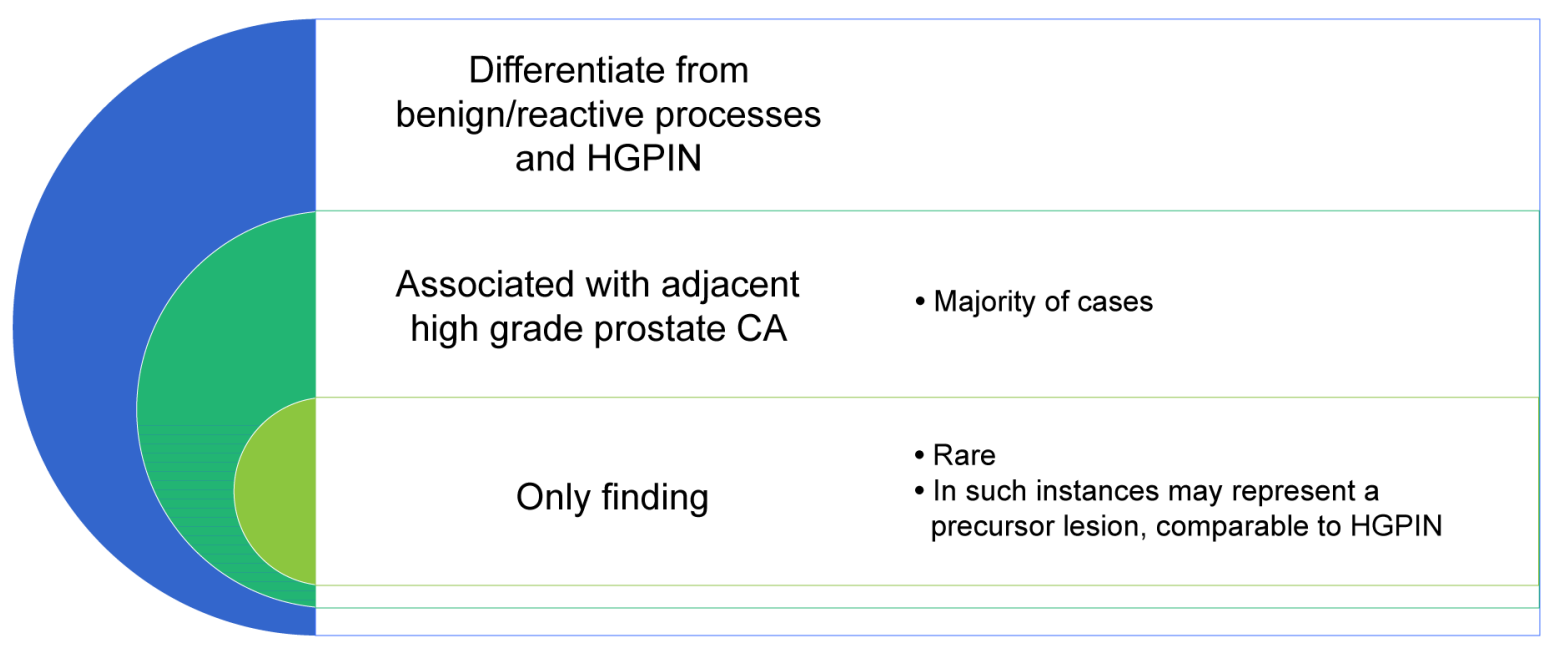

Figure 6. Practical implications of IDC-P.

of being isolated or associated with invasive carcinoma. ISUP members who voted for integrating IDC-P into the Gleason score based their argument on: 1) studies demonstrating that $90 \%$ of prostate resections due to IDC-P only on biopsy, show Gleason score $>7$ invasive carcinoma, 2) IDC-P in the presence of invasive carcinoma is always associated with Gleason score $>7$ carcinoma, and 3) several studies demonstrated correlation of IDC-P with increased stage and worse prognosis. Additionally, distinction between Gleason pattern 4 (cribriform) invasive carcinoma and IDC-P can be challenging; occasionally, it requires performance of immunohistochemical studies on multiple sections of the tumor. Problems arise, however, in the uncommon settings where IDC-P is not found to be closely associated with invasive carcinoma or when invasive carcinoma is not identified in prostate resections [17]. In these cases, the impact of the IDC-P on the patient outcome should be further investigated. Perhaps a distinct grading scheme from the Gleason grading system-one similar to that proposed for grading intraductal carcinoma of the breast-should be utilized to grade IDC-P foci.

\section{Molecular Pathology}

There have been recent advances in molecular testing which has gained importance in prostate cancers. Prostate cancer development and progression involves alterations in numerous genetic pathways and multiple biomarkers have been evaluated for their role in predicting disease and for targeted therapy. These include markers of proliferative index (ki-67), tumor suppression genes such as p53, p21, p27, NKX3, PTEN, retinoblastoma gene and oncogenes such as Bcl2, c-myc, EZH2 and HER2/ neu, adhesion molecules including CD44 and E-cadherin, Pt3K/ akt/mTOR pathway members and apoptosis regulators. These markers along with androgen receptor status and prostate tissue lineage markers such as PSA, prostatic-specific acid phosphatase and prostate-specific membrane antigen can direct patient care. Retrospective studies have shown p53 expression has prognostic significance independent of grade, stage and margin status [24]. Other biomarkers that have also shown a prognostic role include p27, p21 and NKX3.1. Assessment of PTEN loss alone or in combination with ERG fusion can be used in routine practice to identify lower grade disease. Another alteration of importance is the TMPRSS2-ERG fusion which may be helpful to identify aggressive cancers. FISH testing for the fusion or use of immunohistochemistry for evaluation of ERG expression can be used. ERG immunostaining may be especially useful in establishing a diagnosis of carcinoma in biopsies with small foci of atypical glands as well as establishing intraductal carcinoma of prostate over atypical cribriform gland proliferation. PTEN loss can be evaluated by FISH and immunohistochemistry.

A number of commercially available assays are available (Table 3). Decipher genomic classifier is offered by GenomeDx. A study by Ross et al [25] showed that the genomic classifier outperformed clinicopathologic variables in predicting metastatic progression among the cohort of men with biochemical recurrence following RP. The Oncotype DX prostate cancer assay evaluates expression of 12 cancer genes including the androgen pathway (AZGP1, KLK2, SRD5A2 and FAM13C, cellular organization including FLNC, GSN, TPM2 and GSTM2, proliferation by TPX2 and stromal response with BGN and COL1A1. The results are reported as a Genomic Prostate Score. Polaris, which is offered by Myriad Genetics consists of assessment of thirty-one cell-cycle progression (CCP) genes by RT-PCR on RNA extracted from FFPE RP tumor samples. A CCP score is assigned based on the average expression of the CCP genes normalized to 15 housekeeper genes.

Another development in the molecular field is in attempting to identify early detection markers. Bussemakers et al [26] first described PCA3 as one of the most specific markers of prostate cancer. Quantitative real-time PCR assay detecting PCA3 can be applied to blood, urine or prostatic fluid. The use of PCA3 or TMPRSS2-ERG testing has been found to reduce the amount of repeat biopsies without significantly altering the 10-year survival. Another similar test developed by University of Michigan Labs is Mi-Prostate score which determine need for repeat biopsy after a negative prostate biopsy.

\section{Future studies}

More studies are necessary to further elicit the biology of IDC-P and further explore the concept of precursor IDC-P. Additionally, grade assignment to an IDC-P component and its impact on patient care should be further investigated. Further studies reporting the outcome and survival of the patients are crucial to exploit the 
natural history of grade group system, especially grade group 4, in order to develop a more evidence-based grading group system. In near future, molecular pathology will be popular not only for proper diagnosis but also for prognostic evaluation and targeted treatment.

\section{Acknowledgement}

The authors thank Helen Chifotides for her excellent editorial help.

\section{Funding}

None.

\section{Ethics approval and consent to participate}

This study was not involving in any ethics events and human study.

\section{Contributions of each author}

AS and GAS contribute equally writing the paper, reviewing references and taking photos. JYR supervises and reviews the paper and is corresponding author.

\section{Competing interests}

The authors have no financial disclosures.

\section{References}

1. Gleason DF, Mellinger GT: Prediction of prognosis for prostatic adenocarcinoma by combined histological grading and clinical staging. J Urol 1974, 111: 58-64.

2. Delahunt B, Miller RJ, Srigley JR, Evans AJ, Samaratunga H: Gleason grading: past, present and future. Histopathology 2012, 60: 75-86.

3. Epstein JI, Egevad L, Amin MB, Delahunt B, Srigley JR, Humphrey PA: Grading Committee.The 2014 International Society of Urological Pathology (ISUP) consensus conference on Gleason grading of prostatic carcinoma. Am J Surg Pathol 2016, 40: 244-252.

4. Moch H, Humphrey PA, Ulbright TM, Reuter VE: WHO Classification of Tumours of the Urinary System and Male Genital Organs. IARC, Lyon 2016.

5. Amin MB, Greene FL, Edge SB, Compton CC, Gershenwald JE, Brookland RK, Meyer L, Gress DM, Byrd DR, Winchester DP: The Eighth Edition AJCC Cancer Staging Manual: Continuing to build a bridge from a population based to a more "personalized" approach to cancer staging. CA Cancer J Clin 2017, 67: 93-99.

6. Miyai K, Divatia MK, Shen SS, Miles BJ, Ayala AG, Ro JY: Heterogeneous clinicopathological features of intraductal carcinoma of the prostate: a comparison between "precursor-like" and "regular type" lesions. Int J Clin Exp Pathol 2014, 7: 2518-2526.

7. Gordetsky J, Epstein J: Grading of prostatic adenocarcinoma: current state and prognostic implications. Diagn Pathol 2016, 11:25.

8. Iczkowski KA, Paner GP, Van der Kwast T: The new realization about cribriform prostate cancer. Adv Anat Pathol 2018, 25: 31-37.

9. Latour M, Amin MB, Billis A, Egevad L, Grignon DJ, Humphrey PA, Reuter VE, Sakr WA, Srigley JR, Wheeler TM, Yang XJ, Epstein JI: Grading of invasive cribriform carcinoma on prostate needle biopsy: an interobserver study among experts in genitourinary pathology. Am J Surg Pathol 2008, 32: 1532-1539

10. Iczkowski KA, Torkko KC, Kotnis GR, Wilson RS, Huang W, Wheeler TM, Abeyta AM, La Rosa FG, Cook S, Werahera PN, Lucia MS: Digital quantification of five high-grade prostate cancer patterns, including the cribriform pattern, and their association with adverse outcome. Am J Clin Pathol 2011, 136: 98107.

11. Miyamoto H, Hernandez DJ, Epstein JI: A pathological reassessment of organ-confined, Gleason score 6 prostatic adenocarcinomas that progress after radical prostatectomy. Hum Pathol 2009, 40: 16931698.

12. Sabolch A, Feng FY, Daignault-Newton S, Halverson S, Blas K, Phelps L, Olson KB, Sandler HM, Hamstra DA: Gleason pattern 5 is the greatest risk factor for clinical failure and death from prostate cancer after dose-escalated radiation therapy and hormonal ablation. Int J Radiat Oncol Biol Phys 2011, 81: e351-e360.

13. Reese AC1, Landis P, Han M, Epstein JI, Carter HB: Expanded criteria to identify men eligible for active surveillance of low risk prostate cancer at Johns Hopkins: a preliminary analysis. J Urol 2013, 190: 2033-2038.

14. Amin MB, Lin DW, Gore JL, Srigley JR, Samaratunga H, Egevad L, Rubin M, Nacey J, Carter HB, Klotz L, Sandler H, Zietman AL, Holden S, Montironi R, Humphrey PA, Evans AJ, Epstein JI, Delahunt B, McKenney JK, Berney D, Wheeler TM, Chinnaiyan AM, True L, Knudsen B, Hammond ME: The critical role of the pathologist in determining eligibility for active surveillance as a management option in patients with prostate cancer. Arch Pathol Lab Med 2014, 138: 1387-1405.

15. Pierorazio PM1, Walsh PC, Partin AW, Epstein JI: Prognostic Gleason grade grouping: data based on the modified Gleason scoring system. BJU Int 2013, 111: 753-760.

16. Harding-Jackson N, Kryvenko ON, Whittington EE, Eastwood DC, Tjionas GA, Jorda M, Iczkowski KA: Outcome of Gleason $3+5=8$ prostate cancer diagnosed on needle biopsy: prognostic comparison with Gleason 4+ 4= 8. J Urol 2016, 196: 1076-1081.

17. Guo CC, Epstein JI: Intraductal carcinoma of the prostate on needle biopsy: histologic features and clinical significance. Mod Pathol 2006, 19: 1528-1535.

18. Miyai K, Divatia MK, Shen SS, Miles BJ, Ayala AG, Ro JY: Clinicopathological analysis of intraductal proliferative lesions of prostate: intraductal carcinoma of prostate, high-grade prostatic intraepithelial neoplasia, and atypical cribriform lesion. Hum Pathol 2014, 45: 1572-1581.

19. Kovi J, Jackson MA, Heshmat MY. Jackson, and Martin Y. Heshmat: Ductal spread in prostatic carcinoma. Cancer 1985, 56: 1566-1573.

20. Saeter T, Vlatkovic L, Waaler G, Servoll E, Nesland JM, Axcrona $\mathrm{K}$, Axcrona U: Intraductal Carcinoma of the Prostate on Diagnostic Needle Biopsy Predicts Prostate Cancer Mortality: A Population Based Study. Prostate 2017, 77: 859-865.

21. Divatia MK, Ro JY: Intraductal carcinoma of the prostate gland: recent advances. Yonsei Med J 2016, 57: 1054-1062.

22. Van der Kwast T, Al Daoud N, Collette L, Sykes J, Thoms J, Milosevic M, Bristow RG, Van Tienhoven G, Warde P, Mirimanoff RO, Bolla M: Biopsy diagnosis of intraductal carcinoma is prognostic in intermediate and high risk prostate cancer patients treated by radiotherapy. Eur J Cancer 2012, 48: 1318-1325.

23. Bettendorf O, Schmidt H, Staebler A, Grobholz R, Heinecke A, Boecker W, Hertle L, Semjonow A: Chromosomal imbalances, loss of heterozygosity, and immunohistochemical expression of TP53, RB1, and PTEN in intraductal cancer, intraepithelial neoplasia, and invasive adenocarcinoma of the prostate. Genes Chromosomes Cancer 2008, 47: 565-572.

24. Bauer JJ, Sesterhenn IA, Mostofi FK, McLeod DG, Srivastava S, Moul JW: Elevated levels of apoptosis regulator proteins p53 and bcl-2 are independent prognostic biomarkers in surgically treated clinically localized prostate cancer. J Urol 1996, 156: 1511-1516.

25. Ross AE, Feng FY, Ghadessi M, Erho N, Crisan A, Buerki C, Sundi D, Mitra AP, Vergara IA, Thompson DJ, Triche TJ, Davicioni E, Bergstralh EJ, Jenkins RB8, Karnes RJ9, Schaeffer EM1: A genomic classifier predicting metastatic disease progression in men with biochemical recurrence after prostatectomy. Prostate Cancer 
Prostatic Dis 2014, 17: 64-69.

26. Bussemakers MJ, van Bokhoven A, Verhaegh GW, Smit

FP, Karthaus HF, Schalken JA, Debruyne FM, Ru N, Isaacs WB:

DD3: A new prostate-specific gene, highly overexpressed in prostate cancer. Cancer Res 1999, 59: 5975-5979. 